J. Linguistics 37 (200I), 67-100. Printed in the United Kingdom

(C) 200 I Cambridge University Press

\title{
The morphosyntax of WH-extraction in Irish ${ }^{1}$
}

\author{
JAMES MCCLOSKEY
}

\author{
University of California, Santa Cruz
}

(Received I4 June I999; revised 26 July 2000)

It has been widely assumed that the preverbal particles of Irish are complementizers. Given the distribution of the particle $a L$, this assumption provides support for two central claims about WH-movement - that its application is successive-cyclic, and that it is driven by a morphosyntactic feature of the complementizer. However, the claim that $a L$ is a complementizer also has been widely challenged. This paper aims to (re)confirm the original analysis. It argues that the sceptical literature (i) underestimates the morphosyntactic heterogeneity of Irish complementizers, and (ii) restricts attention to an overly narrow subset of constructions in which $a L$ appears.

\section{BACKGROUND}

The paradigm represented by (I)-(3) has been a focus of interest from the time of the earliest work on Irish within the paradigm of generative grammar:

(I) Deir siad gur ghoid na síogaí í. say they C-[PAST] stole the fairies her 'They say that the fairies stole her away.'

(2) an ghirseach a ghoid na síogaí the girl aL stole the fairies 'the girl that the fairies stole away'

(3) an ghirseach ar ghoid na síogaí í the girl aN stole the fairies her 'the girl that the fairies stole away'

In (I), we have a clause into which no A-binding relation reaches, and the clause is introduced by the particle go (combined in this instance with the past tense marker $-r$ ). In (2) we have a clause (a relative clause) into which an $\bar{A}$-binding relation reaches. This is an $\bar{A}$-chain which terminates in a gap (a WH-trace) and the clause is introduced by the particle conventionally written $a L$ (the 'direct relative particle' of traditional grammars). In (3) we have a clause (again a relative clause) into which an $\bar{A}$-binding relation reaches. In this case, the bound element is a pronoun and the clause-

[I] My thanks to two anonymous $J L$ referees for many helpful suggestions. Many thanks also to Ian Roberts for a very useful and interesting e-mail discussion of the issues. 
introductory particle is distinct both from that seen in (I) and from that seen in (2). The particle in (3) is the 'indirect relative particle' of traditional grammars, conventionally represented as $a N$ in recent discussion; in (3), the particle is combined with the same past tense marker $-r$ seen in (I) ${ }^{2}$

Some years ago (McCloskey 1976, I977, 1979, 1990) I argued that all of these clause-introductory particles belong to the same syntactic category. I argued, in fact, that they were all complementizers (members of the functional category $\mathrm{C}$ in more recent terms). That idea has been widely accepted in broader theoretical discussion, and it has played a role in discussions of the nature of WH-movement. In particular, the distribution of $a L$ has been seen as providing support for two key claims about the nature of WH-movement - that it applies in successive-cyclic fashion, and that it is feature-driven. The analysis has played that role because, as is well-known, the particle $a L$ must introduce each clause out of which WH-movement has applied:

(4) rud a gheall tú a dhéanfá

thing aL promised you aL do [COND-S2]

'something that you promised that you would do'

If $a L$ is a particle which registers an application of WH-movement within the clause it heads, then its appearance at the head of each clause in (4) suggests that there has been an application of WH-movement within the limits of each clause - just as the hypothesis of successive-cyclic application requires. In addition, if $a L$ is correctly taken to be a complementizer, then we have support for one of the central hypotheses of recent work - namely, that WHmovement is driven by featural properties of a head ( $\mathrm{C}$ in this case). The reasoning goes as follows. Some property must distinguish $a L$ from other complementizers, since it has both a distinctive form and a distinctive distribution. Assume that this distinctive property consists in its bearing a distinctive syntactic feature. Say we next identify that distinctive feature with the WH-feature - the feature postulated on theoretical grounds in many current conceptions as the driving force behind each application of WHmovement:

(5)

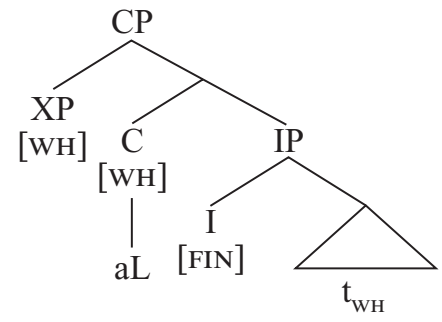

[2] The distinction between (I) and (3) is neutralized in Munster varieties and in some Connemara varieties, which use go in both contexts. 
If we make this move, we succeed in making a natural connection between the distinctive form of the particle and the fact that its appearance is associated with an application of WH-movement.

The larger interest of the phenomenon, then, is that, when viewed in this light, it provides overt morphosyntactic confirmation for the existence of an entity (the WH-feature) originally postulated on the basis of rather abstract theoretical reasoning. This is interesting (in that it represents a case in which an enhanced understanding of the detail of a particular language goes hand in glove with theoretical advance), and reassuring (in that it suggests that the relevant theoretical intuitions might be on the right track). For discussion along these lines see Shlonsky (1992), Chomsky (1995: 267), Rizzi (I990: 55-56), Collins (1996: I05-I06) among many others.

The cornerstone of this proposal, though (the idea that $a L$ is a complementizer), has been widely challenged in more specialist literature (Harlow I98I ; Sells I984; Noonan I992, I994, I997, I999); and, especially, Duffield I995. I persist in believing that the original analysis is fundamentally correct, though, and that the theoretical conclusions derived from it are reasonable ones. In this paper, I want to review the issues and introduce some new considerations, all with the aim of (re)confirming the original analysis, albeit in a new empirical and theoretical setting. I will argue that much of the critical discussion suffers from two defects:

(i) It underestimates the morphosyntactic heterogeneity of the class of complementizers in Irish.

(ii) It restricts attention to an overly narrow subset of the range of constructions in which $a L$ appears.

The basic claim of the present paper is that the deeper one digs into the gore and detail of Irish morphosyntax, the more one finds confirmation for the original analysis and the broader theoretical conclusions that drive it and flow from it.

The first business of the paper, then, is to find ways of arguing about what is or is not a 'complementizer' in Irish. This is a task, happily, which is considerably more difficult than it was twenty years ago. In particular, it has been made more difficult in interesting and subtle ways by Luigi Rizzi's influential proposal that the 'C-system', or the 'C-layer' in clausal organization, is in reality not represented by a single phrasal projection, but is rather a complex phrase structural system which subsumes a number of different heads and their projections (Rizzi I997). I mean to discuss the Irish facts within the context of those proposals. But that will be more easily done after a number of other observations and arguments are put in place. The first part of the paper will therefore proceed on the conservative assumption that the 'C-layer' above TP consists of a single projection CP of a single head C. We will return to Rizzi's proposals in the final section. 


\section{BASIC PROPERTIES}

What is at issue? There is less dispute about the elements $g o$ and $a N$ (seen in (I) and (3), respectively) than there is about the $a L$-particle of (2). The idea that these elements are complementizers has been more widely accepted than has the corresponding idea about $a L$ (though see Sells I984). What has most prominently been in dispute is the claim that the 'direct relative particle' $(a L$ of (2)) is a complementizer. It has been argued by the authors cited above that this element is different enough in its behaviour from $g o$ and $a N$ that it cannot itself be a complementizer. There has been much less agreement about what category it should be taken to belong to.

We can begin to unravel the issues by asking what the fundamental properties of the $a L$-particle are, and asking if those properties are compatible with membership in the category $\mathrm{C}$.

The minimal set of properties of the particle which need to be accounted for seem to be the following seven.

One It appears at the left edge of the clause.

Two It appears only in finite clauses.

Three It forms a prosodic unit with the finite verb.

Four Its appearance is associated with the establishment of a syntactic operator-variable binding relation whose properties are the definitional properties of WH-movement. The particle appears in ALL (finite) constructions which exhibit the standard diagnostic properties of WH-movement (Chomsky I977; McCloskey I979, I985, I990). It appears in relative clauses:

(6) an lá a bhí muid i Machaire Rabhartaigh $\mathrm{t}$

the day aL be [PAST] we in

'the day (that) we were in Machaire Rabhartaigh'

in constituent questions:

(7) Cá fhad a bhí siad fá Bhaile Átha Cliath t?

WH length aL be [PAST] they around Dublin

'How long were they in Dublin?'

in comparative and equative clauses:

(8) Níl sé chomh maith agus a dúradh a bheadh sé t. NEG-is it as good as aL was-said aL be [COND] it 'It's not as good as it was said that it would be.'

(9) níos ísle ná a ceapadh a bheadh sé t more low [COMP] than aL was-thought aL be [COND] it 'lower than it was thought it would be' 
in clefts:

(Io) $\mathrm{Ba}$ i nDoire a dúradh a fuarthas é $\mathrm{t}$ COP[PAST] in Derry aL was-said aL was-found it 'It was in Derry that it was said it was found.'

and 'reduced clefts' (constructions which look mostly like clefts but which lack the copula and its associated morphosyntax):

( I I) Sean-aimseartha a deir muintir an bhaile a tá sí. old-fashioned aL say people the townland $\mathrm{aL}$ is she 'It's old-fashioned that the people of the townland say she is.'

in certain types of manner adverbial clauses:

(I2) mar a chloisimid a dh'imthigh ar Níobé $\mathrm{t}$

as aL we-hear aL went on

'as we hear happened to Niobe'

in certain types of temporal adverbial clauses:

(I3) nuair a tháinig siad 'na bhaile

when aL came they home

'when they came home'

and in emphatic negative constructions involving fronting of an indefinite to a position to the right of the marker diabhal or deamhan (literally 'devil' or 'demon') (see Ó Siadhail I980, I989: 326-330):
(I4) Dheamhan pingin a bhí
devil penny aL be [PAST] at-him
'He hadn't a single penny.'

One important caveat is in order here. As was recognized from the beginning (McCloskey 1979: 54-56), the implicational connection is clear in one direction - if there is an application of WH-movement in a finite clause, then that clause is marked by $a L .^{3}$ Whether the correlation between appearance of the particle and application of WH-movement holds in the opposite direction as well (that is, whether every clause introduced by $a L$ hosts an application of WH-movement) is a different and difficult question. The direct relative particle appears in a variety of clauses for which it is at least not obvious that they involve an application of WH-movement:

(I5) (a) Is amhlaidh a bhí neart céad fear ann. COP[PRES] So aL was strength hundred man in-him 'It is a fact that he had the strength of a hundred men.'

(b) Is minic a dúirt sí go ... COP[PRES] often aL said she $\mathrm{C}$ 'She often said that ...'

[3] Some instances of adjunct-extraction are marked by the particle $a N$. I discuss these cases in detail in independent work. 


\section{JAMES MCCLOSKEY}

(c) Sé rud a bhí neart céad fear ann. COP[PRES] a thing aL was strength hundred man in-him 'It's a fact that he had the strength of a hundred men.'

If there is no believable analysis of such cases (and some others that we will consider in due course) in terms of movement, we will have to assume either that they reflect accidental homophony, or that the relation between $\mathrm{WH}$ movement and the appearance of $a L$ is indirect. Assume, that is, that the bundle of morphosyntactic and phonological characteristics that we abbreviate $a L$ is identified by some feature-bundle $\mathrm{F}_{a L}$. We will then assume a feature co-occurrence restriction (or morphophonological spell-out rule) like (I6):

(I6) $\underset{[\mathrm{WH}]}{\mathrm{C}} \Rightarrow \mathrm{F}_{a L}$

This will leave open the possibility that $\mathrm{F}_{a L}$ might in addition be licensed by some other mechanism - selection by a higher head, for instance. I will abstract away from the possibility of this mechanism in most of what follows. I think that the abstraction is harmless for present purposes.

Five $A L$ triggers the appearance of so-called 'relative' forms of the verb. In certain tenses (present and future), the finite verb may optionally appear in a special form following $a L$. This form is marked by an $-s$ ending and is known in traditional grammars as the 'relative' form of the verb. In our terms, it is probably more accurately called a 'WH-form' of the verb, since it appears not only in relative clauses, but rather in all and only the clausetypes in which $a L$ appears: ${ }^{4}$

(I7) an chéad amhrán eile a bheas againn the first song other aL be [FUT-WH] at-us 'the next song we'll have'

(I8) Nuair a bíos daoine tinn when aL be [PRES-HABIT-WH] people sick 'when people are sick'

(I9) Cá h-uair a thiocfas tú 'na bhaile? what time aL come [FUT-WH] you home 'When will you come home?'

(20) chomh luath agus a thiocfas sé 'na bhaile as early and aL come [FUT-WH] he home 'as soon as he comes home'

Six The appearance of $a L$ is incompatible with the independent expression of sentential negation. Consider the negative equivalent of (2).

[4] These forms have been lost in Munster varieties. 
(2I) an ghirseach ná-r ghoid na síogaí -

the girl NEG-PAST stole the fairies

'the girl that the fairies didn't steal away'

What (2I) exemplifies is that there is 'competition' of a certain kind between the expression of sentential negation and the expression of the particle $a L$. If a clause that one might otherwise have expected to have been headed by $a L$ happens to be negated, then the expression of negation (nár in (2I)) takes precedence over the expression of $a L$. This competition is entirely systematic:

(22) (a) cibé amhrán a tá sibh sásta a rá whatever song aL be [PRES] you [PL] willing say [-FIN] 'whatever song you're willing to sing'

(b) cibé amhrán nach bhfuil sibh sásta a rá whatever song NEG be [PRES] you [PL] willing say [-FIN] 'whatever song you're not willing to sing'

(c) *cibé amhrán a nach bhfuil sibh sásta a rá whatever song aL NEG be [PRES] you [PL] willing say [-FIN] 'whatever song you're not willing to sing'

Seven Most basic of all perhaps - $a L$ may not co-occur with any other element which has been analyzed as a complementizer.

I want to begin by claiming that these seven fundamental properties are straightforwardly compatible with membership in the category of complementizers.

The first property (that $a L$, in general, appears on the left periphery of the clause) is easily understood if complementizers are heads $\mathrm{C}$, which project clauses $\mathrm{CP}$, and if heads, in this language-type at least, are always initial. Certain exceptions to the pattern are understandable given other properties to be considered below.

The second property (the restriction to finite clauses) is one which $a L$ shares with all other claimed members of the class of preverbal clauseintroductory particles, and also with such elements as English that, French $q u e$, German $d a \beta$ and so on. It can be interpreted as the property of selecting a tensed TP (or more exactly $-\mathrm{f}$-selecting a finite $\mathrm{T}$ ). This is a property which it shares with a wide variety of other elements uncontroversially assigned to the category $\mathrm{C}$ - in Irish, and in many other well-studied languages.

The third property (that $a L$ forms a prosodic unit with the finite verb) is a fully general property of complementizers in Irish. These matters are discussed in detail in McCloskey (1996), where it is argued at some length that complementizers in general in Irish are subject to a requirement that they lower, adjoining to the Tense element, and forming a morphological and prosodic complex with the finite verb. According to this proposal, the examples in (23): 


\section{JAMES MCCLOSKEY}

(23) (a) an deoch a d- ól tú the drink aL PAST drink you 'the drink that you drank'

(b) an deoch a $-\mathrm{r}$ ól tú í the drink aN PAST drink you it 'the drink that you drank'

will include the substructures seen in (24). The complex heads seen in (24) (the 'verbal complexes') are formed by the joint action of verb raising and C-lowering.

(24) a

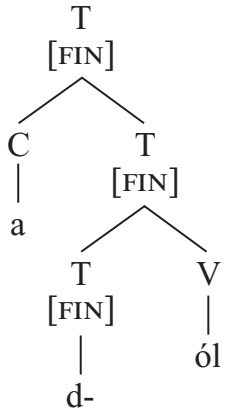

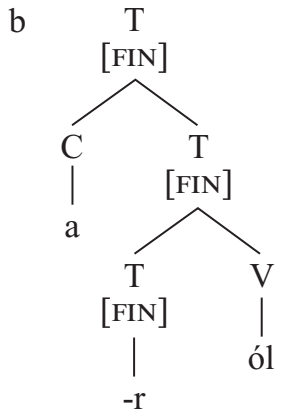

These are the structures which are presented to the morphophonology and the prosody of the language. (23a)/(24a) involves the direct relative particle $a L ;(23 b) /(24 b)$ involves the indirect relative particle $a N$. The only difference between the two derived structures (discussed in detail in the next section) is that $a L$ demands the past tense marker $d$ - (which leans to the right), while $a N$ demands the past tense marker $-r$ (which leans to the left). ${ }^{5}$ Similar understandings apply in the case of the other members of the category C. If this approach is roughly on the right track (and it is worth stressing that the arguments presented in McCloskey (1996) have nothing at all to do with the concerns of the present paper), then the third property of $a L$ also falls into place on the assumption that it is a member of the category $\mathrm{C}^{6}{ }^{6}$

[5] The observations and analysis offered in McCloskey (I996) also account for some apparent exceptions to the first claim made above - that $a L$ is initial in its clause. In a range of cases, the initial position of the particle with respect to adverbial or fronted elements is hidden by the fact that the particle lowers to the right across them. See McCloskey (I996) for detailed discussion.

[6] Cottel (I995) argues against the C-lowering analysis, and argues that $\mathrm{C}$ and I should both have an independent specification of Tense. This last claim I think is entirely right (and it has not, as far as I know, been much in dispute). Cottel, though, seems to assume that the lowering analysis is solely or principally motivated by the desire to account for composite forms like gur or ar. This does not seem to me to be the case, though. Even if one maintains that the past tense markers $-r$ and $d$ - originate in the C-system, there is still a body of fact to be accounted for - the facts adduced in McCloskey (I996), the fact that the sequence of $\mathrm{C}$, Tense-marker and finite verb forms a prosodic unit, and the further fact that that incorporation has syntactic consequences (see (58) and associated discussion below, for 
As for the fourth property, we can account for this directly as sketched in section I above. If we assume that $a L$ is a head $\mathrm{C}$ which determines an $\overline{\mathrm{A}}$ specifier position, and in addition that it bears a feature which will be satisfied by way of movement of a phrase into that specifier position, then application of WH-movement will entail appearance of $a L$. This is the 'traditional' analysis in a modern guise - a guise which renders understandable many of the properties which seemed theoretically anomalous in I979 (McCloskey I979: I 57). We might as well follow convention and name the distinctive feature of $a L$ ' $W H$ ', since the properties just listed are close to being a definition of the feature $\mathrm{WH}$ as it is presently understood.

The fifth of the seven core properties is the fact that $a L$ licenses the appearance of WH-forms of the verb. This too is straightforwardly accounted for if $a L \mathrm{f}$-selects a $\mathrm{T}$ which bears some morphosyntactic feature (call it $\mathrm{F}_{\mathrm{wH}}$ ), which will be checked when an appropriate verbal form raises to $T .{ }^{7}$

Consider now the sixth core property of $a L$. This is the pattern of complementary distribution that holds between expression of $a L$ and the expression of sentential negation. Here too we are dealing with a property of all complementizers in the language (regardless of tense, aspect or mood). (25)-(27) illustrate this for a range of complementizers and tenses.

(25) (a) Creidim go gcuirfidh sí isteach ar an phost. I-believe $\mathrm{C}$ put [FUT] she in on the job

'I believe that she'll apply for the job.'

(b) Creidim nach gcuirfidh sí isteach ar an phost.

I-believe NEG C put [FUT] she in on the job

'I believe that she won't apply for the job.'

(26) (a) Creidim gu-r chuir sí isteach ar an phost.

I-believe C-PAST put she in on the job

'I believe that she applied for the job.'

(b) Creidim ná-r chuir sí isteach ar an phost.

I-believe C[NEG]-PAST put she in on the job

'I believe that she didn't apply for the job.'

instance). These are the facts which the hypothesis of C-lowering is supposed to account for and they are not dealt with in Cottel's critique. Cottel (I995: I I8) disputes one of the factual claims made in McCloskey (I996) (that negative complementizers in complement clauses follow phrases fronted by 'Narrative Fronting'), but fails to mention that the original factual claim was based on attested examples. If there are speakers for whom the relevant examples are ungrammatical, this indicates that there are speakers for whom Narrative Fronting is a root process - not a surprising conclusion, and one which has no implications, as far as I can tell, for the validity of the C-lowering hypothesis.

[7] Within the terms of reference of Chomsky (I998), we can identify $\mathrm{F}_{\mathrm{wH}}$ with the WHfeature itself. $\mathrm{C}$ will be taken to bear, in addition, an EPP-like feature added after construction of the phase $\mathrm{CP}$ is complete, which will in turn force raising to the associated specifier-position. 


\section{JAMES MCCLOSKEY}

(27) (a) A' gcuirfidh sí isteach ar an phost? INTERR put [FUT] she in on the job 'Will she apply for the job?'

(b) Nach gcuirfidh sí isteach ar an phost? NEG INTERR C put [FUT] she in on the job 'Won't she apply for the job?'

(28) (a) an post a-r chuir tú isteach air the job aN-PAST put you in on-it 'the job that you applied for'

(b) an post ná-r chuir tú isteach air the job NEG-PAST put you in on-it 'the job that you didn't apply for'

That is, the property of being incompatible with the independent expression of negation is a quite general property of complementizers, and one which we will see holds even when a broader class of C-elements is taken into consideration. These observations suggest in combination that the rules (lexical or morphological) which determine the form of functional elements respond systematically when they see the feature [NEG] on the category $\mathrm{C}$. The rules needed must have the effect in (29). ${ }^{8}$

(29)

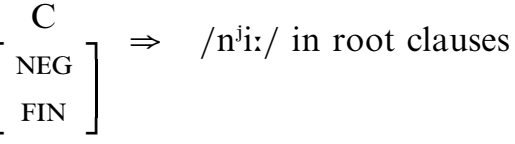

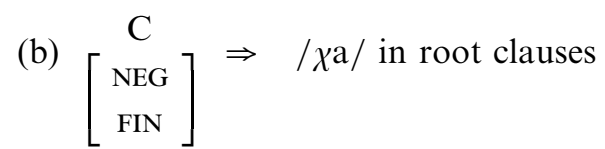

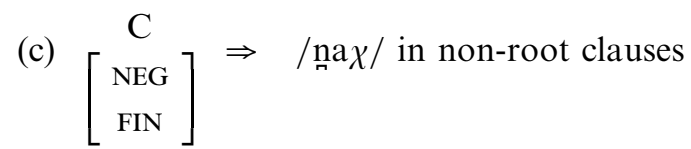

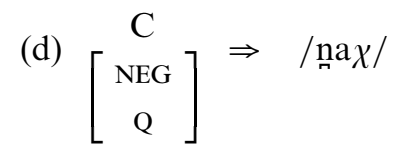

The so-called 'past tense forms' of these elements result from their composition with the $-r$ marker of the past tense, yielding the forms seen in table I.

[8] The negative marker cha in (29b) occurs only in Ulster varieties. 
MORPHOSYNTAX OF WH-EXTRACTION IN IRISH

\begin{tabular}{|c|c|c|}
\hline Composition & Orthographic & Phonemic \\
\hline ní $+-\mathrm{r}$ & níor & $/ \mathrm{n}$ iitr/ \\
cha $+-\mathrm{r}$ & char & $/$ var/ \\
nach $+-\mathrm{r}$ & nár & $/ \bullet$ atr/,/•avbr/ \\
\hline
\end{tabular}

Table 1

Once again, the relevant combinatorial processes seem not to be different from those at play in the case of other complementizers as seen in table 2.

\begin{tabular}{|c|c|c|}
\hline Composition & Orthographic & Phonemic \\
\hline go + -r & gur & $/ \mathrm{gbr} /$ \\
$\mathrm{a}+\mathrm{-r}$ & ar & $/ \mathrm{br} /, / \mathrm{er} /$ \\
\hline
\end{tabular}

Table 2

The phonology of 'past tense forms' of preverbal particles (complementizers for us) is derivable from straightforward concatenation (of $\mathrm{C}$ with $-r$ ) in all cases but one. In the case of non-root negation nach $(/$ nax/), simple concatenation yields $/$ na $\chi \mathrm{r} /$ - an unpronounceable syllable. This phonotactic dilemma is resolved in different ways in different dialects - by way of deletion of $/ x /$ in most, by way of insertion of an epenthetic $/ \partial /$ in others.

Different views are possible as to how $\mathrm{C}$ acquires the feature [NEG]. The feature could be there as a matter of inherent lexical specification, or it might come to reside in $\mathrm{C}$ as a consequence of raising of a lower independent head Neg to C (Guilfoyle 1990, Duffield 1995) (nor are the two lines of analysis necessarily incompatible). What is important for present concerns is that the issues and mechanisms are identical for $a L$ and for elements whose analysis as members of the category $\mathrm{C}$ is uncontroversial.

Finally, the seventh property. The particle $a L$ may not co-occur with any (other) complementizer. If $a L$ is itself a member of the category $\mathrm{C}$, then (in the absence of CP-recursion structures) its presence will preclude the appearance of any other member of the same category.

Putting all this together, it seems to me to be reasonable to maintain that all seven core properties of $a L$ are straightforwardly in harmony with the idea that it belongs to the category $\mathrm{C}$.

\section{MORPHOSYNTACTIC DIFFERENCES BETWEEN $a L$ AND OTHER COMPLEMENTIZERS}

There are also, however, some salient morphosyntactic differences between $a L$ and other elements whose identification as complementizers is uncontroversial. These are the properties which have been central in the debate over the categorial status of $a L$. 


\section{JAMES MCCLOSKEY}

Difference $A$ The direct relative particle induces the initial mutation known as lenition. It has been claimed that the exclusive (or at least characteristic) mutation-effect triggered by elements of $\mathrm{C}$ is eclipsis (also known as 'nasalization'). For discussion, see Stenson (I98I) and especially Duffield (I995: 83-90). Compare (30) with (3I), for instance. In (30), the presence of the complementizers ( $g o$ in (30a), interrogative $a^{\prime}$ in (30b) and $a N$ in (30c)) induces eclipsis on the following finite verb. The mutation is signalled orthographically by the presence of the initial $g$ prefixed to the verb.

(30) (a) Creidim go gcuirfidh sí isteach air.

I-believe $\mathrm{C}$ put [FUT] she in on-it

'I believe that she'll apply for it.'

(b) A' gcuirfidh sí isteach air?

INTERR put [FUT] she in on-it

'Will she apply for it?'

(c) Céacu post a gcuirfidh sí isteach air?

which job aN put [FUT] she in on-it

'Which job will she apply for?'

In (3I), on the other hand, the particle $a L$ induces the initial mutation known as lenition, indicated orthographically by the $h$ which follows the initial of the verb.

(3I) (a) na mná a chuireann - isteach ar phostanna mar seo the women aL put [PRES] in on jobs like this 'the women who apply for jobs like this'

(b) I nDoire a chaith sé an oíche.

in Derry aL spent he the night

'It was in Derry that he spent the night.'

Difference $B$ This contrast has to do with the distribution of 'dependent' forms of the irregular verbs. The point here is that the direct relative particle does NOT demand the appearance of 'dependent' forms of the irregular verbs, whereas (it has been claimed) all other complementizers do. Only a small group of irregular verbs (between ten and thirteen depending on dialect) exhibit this distinction. These verbs have suppletive forms known as 'dependent' forms, whose appearance is triggered by certain preverbal particles, almost all of them uncontroversially analyzed as complementizers. Compare (32) with (33). In (32a), the verb 'saw' appears in its dependent form because it is preceded by the complementizer $g o$; in $(32 \mathrm{~b})$, the verb appears in the dependent form because it is preceded by the interrogative complementizer $a^{\prime}$; and in (32c), appearance of the dependent form is triggered by the markers of negation $-n i$ or $\operatorname{ch} a(n) .{ }^{9}$

[9] Cha has an allomorph chan before vowels. Since lenited $f$ (written $f h$, as in (32c)) is null, the stem here counts as vowel-initial and the form chan is required (Armstrong 1975). 
(32) (a) Creidim go bhfaca mé do nighean. I-believe $\mathrm{C}$ see [PAST] I your daughter 'I believe that I saw your daughter.'

(b) An bhfaca tú mo nighean? INTERR see [PAST] you my daughter 'Did you see my daughter?'

(c) Ní (chan) fhaca tú mo nighean. NEG see [PAST] you my daughter

'You didn't see my daughter.'

In (33), on the other hand, the same verb appears in its non-dependent form when preceded by $a L$.

(33) an bhean a chonaic tú -

the woman aL see [PAST] you

'the woman that you saw'

This is the same form of the verb which appears in root clauses, in which there is, in the general case, no audible preverbal particle at all:

(34) Chonaic tú í.

see [PAST] you her

'You saw her.'

Difference $C$ The direct relative particle co-occurs with the past tense marker $d(o)$ rather than with the marker $-r$ which attaches, it is claimed, to all other C-elements. This is illustrated in (35) and (36). The past tense marker $d$-appears in root clauses (as seen in (35a)) and following the direct relative particle $a L$ (as seen in $(35 \mathrm{~b}))^{10}$

(35) (a) D-ól siad an t-uisce PAST-drank they the water 'They drank the water.'

(b) an ghirseach a d-ól an t-uisce the girl aL [PAST]-drank the water 'the girl that drank the water'

In most (but not all) modern varieties of the language, this particle is audible only before a vowel-initial stem. I will assume here, with most work in this tradition, that it is syntactically present in other cases as well.

Other preverbal particles, whose status as complementizers is less in dispute, co-occur with the past tense marker $-r$, which leans to the left. This is illustrated for the marker of subordination, the interrogative marker, the marker of root negation and the marker of subordinate negation, respectively, in $(36 \mathrm{a}-\mathrm{d})$.

[I0] The $d$ - prefix also attaches to (vowel-initial) stems in the conditional. 


\section{JAMES MCCLOSKEY}

(36) (a) Deir siad gu-r ól siad an t-uisce. say they C-PAST drank they the water 'They say that they drank the water.'

(b) A-r ól tú a gcuid uisce? INTERR-PAST drank you their portion water 'Did you drink their water?'

(c) Níor (cha-r) ól tú a gcuid uisce. NEG-PAST drank you their portion water 'You didn't drink their water.'

(d) Deir siad ná-r ól siad an t-uisce. say they C[NEG]-PAST drank they the water 'They say that they didn't drink the water.'

The claim that is explicit or implicit in the works cited earlier is that these three morphosyntactic tests are reliable as identifiers of the category $\mathrm{C}$ in Irish. Since with respect to all three tests, $a L$ contrasts with the other elements we have considered, it would be wrong, it is argued, to group it with them in the category C. I will occasionally refer to the properties of $g o$ (eclipsis, selection of $-r$, selection of the dependent form of irregular verbs) as the morphosyntactic profile of the 'true' complementizer.

I want to make a general observation before proceeding to the more detailed discussion. The grammatical domains at the focus of this investigation are fraught with idiosyncrasy and variations particular to individual items. Consider the initial mutations for instance. One of the properties that distinguishes $a L$ from uncontroversial members of the class of complementizers is the fact that it triggers the lenition mutation on a following initial. Is this mutation-effect an idiosyncrasy, particular to this item, or does it reflect a general pattern, useful for diagnosing category membership? The answer is not obvious. As is well known, for instance, prepositions vary widely and idiosyncratically in the mutations they induce. Nor is this idiosyncrasy restricted to the lexical (open-class) categories. The particle $\operatorname{cha}(n)$ functions as a marker of root negation in most Ulster varieties, for instance. Its mutation-inducing properties vary considerably from one sub-dialect to another, but one of the more commonly attested patterns is the following (see, for instance, Ó Searcaigh (I 939: 297-298)). It lenites in the general case:

(37) Cha cheangaileann sé é.

NEG tie [PRES] he it

'He doesn't tie it.'

It induces no mutation on a verb with initial $s$ :

(38) Cha sabhálann sé ariamh an féar. NEG save [PRES] he ever the hay

'He never saves the hay.' 
But it eclipses an initial $t$ :

(39) Cha dtabharann sé bia dófa. NEG give [PRES] he food to-them

'He doesn't give them food.'

As for the distribution of the past tense prefixes $d$ - and $-r$, the negative marker $n i$ in most varieties takes $-r$ :

(40) (a) Ní ólann sí ariamh tae.

NEG drink [PRES] she ever tea

'She never drinks tea.'

(b) Ní-or ól sí ariamh tae.

NEG-PAST drank she ever tea

'She never drank tea.'

But in many West Kerry varieties, $n i$ combines with $d$-, as shown in (4I), from Ó Sé (1983: 230). ${ }^{11}$

(4I) (a) Ní dh' fhágadar $\quad \ldots$

NEG PAST leave [PAST-P3]

'They didn't leave ...'

(b) Ní dh' úsáid sé ...

NEG PAST used he

'He didn't use ...'

In the face of this kind of variation, it is unclear (to me at any rate) how one assesses whether a given morphosyntactic effect (say, the fact that $a L$ induces lenition, or that it combines with $d$ - rather than $-r$ ) reflects a local idiosyncracy or some more general pattern. The larger methodological issue is this: do the gory details of morphosyntax provide reliable clues about syntactic category membership? Duffield (I995), in particular, is a sustained investigation of the position that they do. My own instinct is to be cautious.

\section{OTHER COMPLEMENTIZERS}

Caution is all the more advised when it is realized that the body of work just summarized has focussed on a relatively small class of complementizers - the particles which introduce complement clauses, negative clauses, interrogative clauses and clauses into which a relation of $\bar{A}$-binding reaches. There are other elements, though, which are clearly complementizers but which have not to date figured in these discussions.

[II] Note that the marker of negation lenites $d$ - in (4I). The relative particle $a L$ behaves similarly in this dialect, as does conditional má, discussed below (Ó Sé (I983: 232), Ó Siadhail (1989: 177)). 
Irish has two words for if. $D a ́$ is used in counterfactual conditionals, as shown in (42); má is used in 'simple' or 'open' conditionals, as shown in (43).

(42) (a) Dá leanfadh sé dá chúrsa, bheadh deireadh leis.

if follow [COND] he of-his course be [COND] end with-him

'If he had persisted in his course, he'd have been finished.'

(b) Dá ndéanfá feabhsú ar bith d'ardófaí

if do [COND-S2] improvement any raise [COND-IMPERS]

an cíos

the rent

'If you were to implement any improvement, the rent would be raised.'

(43) (a) Má leanann tú de do chúrsa, beidh

if follow [PRES] you of your course be [FUT]

aithreachas ort.

regret on-you

'If you persist in your (present) course, you'll be sorry.'

(b) Má bhí tú ann chonaic tú í.

if be [PAST] you there saw you her

'If you were there, you saw her.'

Counterfactual dá has the same morphosyntactic profile as the 'true' complementizers such as $g o$. That is, it eclipses the initial of a following finite verb (see the initial $g$ of the finite verb in (44a)), and it forces appearance of dependent forms of the irregular verbs. This can be seen in (44b), in which we have the dependent form (tabharfadh) of the verb 'give' rather than the independent form (bhéarfadh). ${ }^{12}$

(44) (a) Dá gcuirfeá isteach ar an phost, gheofá é. if put [COND-S2] in on the job get [COND-S2] it 'If you had applied for the job, you would have got it.'

(b) Dá dtabharfadh sé domh é, chuirfinn i dtaisce é. if give [COND] he to-me it put [COND-SI] in store it 'If he would give it to me, I would put it away for safe keeping.'

The má of simple conditionals, however, shows none of these morphosyntactic properties. It lenites the initial of the finite verb:

(45) Má phósann tú an siostalóir

if marry [PRES] you the hackler

'if you marry the hackler'

It demands independent rather than dependent forms of the irregular verbs. Chuaigh in (46) is the independent form of the verb 'to go'; the dependent form is deachaigh.

[I2] One cannot ask which form of the past tense prefix dá combines with, since its status as counterfactual forbids this combination. It must be followed by the conditional or, in formal or archaic varieties, by the past subjunctive. 
(46) (a) Má chuaigh sé ann if go [PAST] he there 'if he went there'

(b) *Má dheachaigh sé ann if go [PAST] he there 'if he went there'

It co-occurs with past tense $d$ - rather than $-r$ :

(47) (a) Má d' inis sé bréag if PAST told he lie 'if he told a lie'

(b) *Má-r' inis sé bréag if-PAST tell he lie 'if he told a lie'

In short, má shows all the morphosyntactic characteristics of the direct relative particle $a L$ (bar one, as we shall see).

Yet $m a ́$ is clearly a complementizer. The typological evidence for this conclusion is strong (Kayne I983, den Besten I983, Rizzi \& Roberts I989, Vikner I99I). And evidence internal to Irish suggests the same conclusion.

Like other complementizers (and like counterfactual dá), má may not cooccur with an independent expression of negation:

(48) *Má nach gcuireann tú isteach ar an phost

if NEG put [PRES] you in on the job

'if you don't apply for the job'

Rather, one finds the composite form mura (muna or mur in some dialects) ${ }^{13}$

(49) Mura gcuireann tú isteach ar an phost

if NEG put [PRES] you in on the job

'if you don't apply for the job'

$M a ́$ also occurs in one of the characteristic syntactic positions in which complementizers occur. There is in Irish a class of elements, many of them apparently prepositions, which select CPs of various types and express a range of adverbial meanings. The element $c e ́$ selects a CP headed by go, for instance, to express 'though':

(50) Cé go raibh sé breoite although $\mathrm{C}$ be [PAST] he ill 'although he was ill'

[13] The negative conditional combines with past tense $-r$ in the familiar way:

(i) Murar chaith siad seachtain ann ... if-[PAST] spend they week there 'If they didn't spend a week there, ...' 


\section{JAMES MCCLOSKEY}

Let us use the neutral term 'subordinators' for elements like cé in (50) (they are probably all in fact prepositions). Table 3 gives an impression of the combinatorial possibilities that exist. Notice in particular that all of the standardly recognized complementizers except the interrogative marker occur in the second position of this frame. We will return to other possibilities shortly.

\begin{tabular}{|c|c|c|}
\hline Subordinator & Comp selected & Meaning \\
\hline nó & go & until, so that \\
chun & go & so that \\
murach & go & if it weren't for \\
mar & $\mathrm{aN}$ & where \\
ach & $\mathrm{aN}$ & as soon as, until \\
mar & $\mathrm{aL}$ & as \\
nuair & $\mathrm{aL}$ & when \\
\hline
\end{tabular}

Table 3

Of particular interest to us here is the element sul, meaning 'before'. This element in many varieties selects clauses headed by the 'indirect relative particle' (see example (3) above):

(5I) sul a-r thóg siad an teach

before aN-PAST raised they the house

'before they built the house'

In many varieties, however, sul selects clauses headed by má (De Bhaldraithe (I953: I79), Lucas (I979: 20I), Ó Siadhail (I989: 323)):

(52) (a) i bhfad sul má fuair sé bás

long before if got he death

'long before he died'

CFIo6

(b) sul má bheidh a fhios aige tada

before if be [FUT] knowledge at-him nothing

'before he knows anything'

CFI29

The fact that má participates in this syntactic pattern dovetails with the other evidence which suggests that it (like its close relative, the marker of counterfactual conditionals, $d a$ ) is a member of the category C. ${ }^{14}$

But if this much is correct, then the clustering of morphosyntactic properties which characterize both má and the direct relative particle $a L$ must be compatible with membership in the category $\mathrm{C}$. There are simply two

[14] De Bhaldraithe (I953: I79) reports that in the Galway variety he describes $m a ́$ is also selected by the preposition as ucht in the meaning 'because'. 
subclasses (at least) of complementizer - one with the cluster of properties shown by go, $a N$ and $d \dot{a}$; one with the cluster of properties shown by má and $a L$. Given their semantic, syntactic and prosodic similarities, it would be particularly wrong, it seems to me, to insist that the marker of counterfactual conditionals ( $d a ́$ ) and the marker of simple conditionals ( $m a ́$ ) must belong to different syntactic categories just because they differ in their interaction with tense-marking, initial mutations and the like. This conviction is strengthened when it is observed that in many Munster varieties, má also occurs in the counterfactual use, but with the same clustering of morphosyntactic characteristics (lenition of the verb and so on): (53a) is from Ó Sé (1983: 255); see also O Siadhail (I989: 32I), from which (53b) is taken:

(53) (a)

Má dhéanfá féin aon fheabhsú ar an dtalamh

if do [COND-S2] REFL any improvement on the land 'If you yourself should make any improvements on the land'

(b) nó, má dhéanfadh, do mharódh Mac Amhlaoibh iad or if do [COND] PAST kill [COND] them 'or, if he had, Mac Amhlaoibh would have killed them'

If this is right, it must further be true that the morphosyntactic properties which distinguish má from dá, whatever their source, are ultimately unrevealing about syntactic category membership (see also the discussion of (4I) above).

If it is granted, though, that $m a ́$ is a complementizer, then nothing stands in the way of identifying $a L$ as a complementizer.

It might be worth completing the cycle of observation by noting that sul can also select the direct relative particle $a L$ in some varieties (in the Irish of Inis Meáin, for instance):
(a) sul bheas sé mar fhear scéil orm before be [FUT-WH] he as man story [GEN] on-me 'before he acts as a tattle-tale on me'
(b) sul fhliuchfas mise sibh before wet [FUT-WH] I you [PL] 'before I wet you'

In (54) the relative particle $a L$ is phonologically elided (as it frequently is in other contexts), but its presence is indicated surely by lenition of the initial of the finite verb and by the appearance of 'relative' (that is, WH) forms of the finite verb. The parallel behaviour of $a N, m a$ and $a L$ here (all selected by the subordinator sul) is of course expected if they are all three members of C. ${ }^{15}$

[15] The cases in (54) must be added to the set of cases in which $a L$ is not obviously associated with an application of WH-movement (see the discussion surrounding example (I5) above). If these uses of the particle are analyzed as being distinct from, but homophonous 
The fact that conditional $m a$ and the direct relative particle $a L$ share all three morphosyntactic properties might suggest that these three properties are related in some non-accidental way (perhaps if an item has one, then it has all three). This could be true, but any attempt to link the three properties will need to say something about the root negation element $n i$. This element, in most varieties, shares one property with $m a ́$ and $a L$-it lenites the initial of a following finite verb. But it differs in the other two (it combines with the past tense marker $-r$ rather than with $d$-, and it demands dependent, rather than independent, forms of the verb). The other marker of root negation (cha), on the other hand, shows more of the morphosyntactic profile of the 'true' complementizer. It induces eclipsis (sometimes, but see (37)-(39) above), selects $-r$ in the past tense and demands dependent forms of the irregular verbs. In the West Kerry variety described at (4I) above root negation $n i$ shares two properties with $m a ́$ and $a L$, in that it induces lenition and it demands the past tense marker $d$-. However it shares its third property (demanding dependent forms of the irregular verbs) with the "true complementizers'. There may be some systematicity here, but it is not obvious to me what it is.

Returning to the central theme, and putting all this together, the conclusion which emerges is that the morphosyntactic properties of $a L$ are, as it turns out, in harmony with its belonging to (one morphosyntactic subcategory of) the category $\mathrm{C}$ - the same subcategory to which má belongs. The single property that separates $a L$ from the complementizer má is that the former, but not the latter, can license WH-forms of the verb. That is: what sets $a L$ apart is simply its 'WH-ness'.

This last observation tells against an alternative view of the syntax of $m a ́$ that might be envisioned - namely that it is an element (perhaps a 'subordinator' like those discussed at p. 84 above) which itself selects $a L$ (whatever category that might belong to). This proposal would account for the morphosyntactic similarities between $m a ́$ and $a L$ by assuming that every occurrence of $m a ́$ implies a (phonologically elided) occurrence of $a L$. The silent occurrence of $a L$ would then be responsible for the various morphosyntactic commonalities between $m a ́$ and $a L$ that we have been discussing here. This is almost certainly the right analysis for a case like (55), in which the preposition $o$ ('from') selects a finite clause in the meaning 'since' (temporal and causal):

(55) (a) Ní-or mhothaigh mé iomrá air ó d' imigh sé. NEG-PAST heard I report on-him from PAST leave he 'I've heard nothing of him since he left.'

with, the instance of $a L$ which appears in WH-constructions, then they should be added to the list of complementizers which exhibit the morphosyntactic profile of $m a ́$ and $a L$ rather than the profile of the 'true' complementizer. 
MORPHOSYNTAX OF WH-EXTRACTION IN IRISH

(b) Ó tharla go bhfuil tú anseo from happen [PAST] $\mathrm{C}$ be [PRES] you here

'Since it happened that you're here'

The difficulty here is that presence of the elided $a L$ below $m a$ should be detectable in the licensing of WH-forms of the verb - as happens in the case of (54), and as also happens in the case of $o$ (Christian Brothers I960: 193, $\S 386$ (iii)):

(56) (a) ó

thosaíos duine uirthi

from begin [PRES-WH] person on-it

'from (the time) that a person starts on it'

(b) ó bheas siad ráithe d' aois

from be [FUT-WH] they quarter-year of age

'from (the time) that they are three months old'

IM095

IMI072

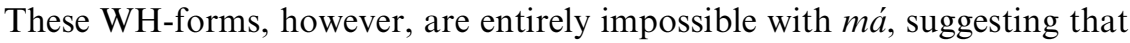
there is no silent $a L$ in conditional structures. Furthermore, $o$ permits the independent expression of negation:

(57) ó nach raibh clann acu since NEG C be [PAST] family at-them

'since they had no children'

These patterns are as expected if $o$ is a 'subordinator' of the type discussed at p. 84 above - a preposition which selects a CP headed by $a L$. (57), then, reflects the usual behaviour of $a L$ in a negative clause.

But $m a ́$ behaves differently. As we have already seen ((48), (49) above), it forbids the option in (57) and shows instead a distinctive negative-conditional form mura, analogous to the negative forms of other complementizers. If $m a$, like $o$, selected $a L$, then (48) should be grammatical, on a par with (57).

Finally, the fact that $m a ́$ and $a L$ can themselves be selected by 'subordinators' also confirms the status of both as complementizers (p. 84 above).

I have gone to some length here to defend the position that má is a complementizer because it is, in my view, a crucial test case for the reliability of the morphosyntactic tests that have been used to argue that $a L$ is not a complementizer. It seems relatively clear that $m a ́$ is a member of the category $\mathrm{C}^{16}$ and yet it shares with $a L$ all the crucial morphosyntactic traits that distinguish it from $g o N .^{17}$

[I6] It is certainly not a marker of Tense, a marker of Topic-hood, or a marker of Focus - the alternative proposals that have been made about the category of $a L-$ see the following section.

[17] There is a range of other elements which one might investigate in similar detail and which would yield, I think, similar conclusions. Consider, for example, the optative markers which select a subjunctive clause - affirmative (i) and negative (ii). 


\section{Alternative proposals}

So far, we have been dealing with arguments that on morphosyntactic grounds $a L$ should be analyzed as being something other than a complementizer. The burden of the discussion has been that when a broader range of facts is considered, the morphosyntactic properties of $a L$ are not, in fact, inconsistent with its being a complementizer. I want to turn at this point to the positive proposals that have been advanced about what category (if not C) $a L$ should be taken to belong to.

Among those who have been sceptical of the claim that $a L$ is a complementizer, there has been less agreement about what category it does belong to - although the consistent thread that runs through the available proposals is that $a L$ is more closely related to the Tense element than the other preverbal particles are.

Harlow (I98I) takes $a L$ to be a WH-pronoun in COMP. ${ }^{18}$ In part, this proposal is motivated by some of the morphosyntactic concerns considered in detail in the previous section (which are taken to show that $a L$ is not a complementizer), in part by the goal of analyzing $a L$ as a proper governor (in the sense of the ECP) for WH-traces. The first set of concerns has been addressed in the previous section. The second concern is more difficult to assess in current contexts. It is worth pointing out, though, that there is no inherent contradiction between being an (indexed) complementizer and being a proper governor for ECP purposes (see especially Hale I978, Lasnik \& Saito I 992 and, for more general discussion, Rizzi I990). And it is the role of $a L$ as a proper governor, rather than its role as a pronoun, that is central to Harlow's proposals. As far as I can tell, the core elements of that analysis can be reconstructed in a fairly straightforward way within the terms of the general framework developed here and in McCloskey (I996). In a sense, this is exactly what Rizzi (I990: 55-56) does (see also Chung \& McCloskey I987 for relevant discussion). The proposal that $a L$ is itself a $\mathrm{WH}$-pronoun is at odds with its similarities with elements that are fairly clearly com-

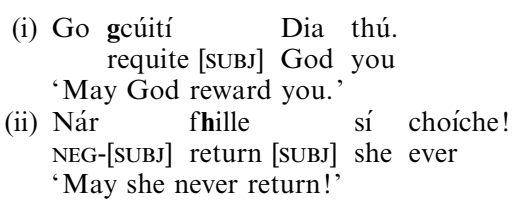

Affirmative go seems to be parallel to the optative use of French que and German daß (Duffield 1995: 87) and for this and other reasons has been standardly analyzed as a complementizer. As befits a 'true' complementizer, it eclipses and selects dependent forms of the irregular verbs. Negative nár in this use is presumably also a complementizer. Yet it, by contrast, lenites. In further contrast, though, it resembles 'true' complementizers ( $g o$ and so on) in requiring what seem to be dependent forms of the irregular verbs (De Bhaldraithe 1953: 234), though distributional and morphological restrictions on the subjunctive make it hard to be sure.

[I8] The proposal is withdrawn in later work - Harlow (1983). 
plementizers, and also with its appearance in EACH clause in which WHmovement has applied (Sells I984: I 26-I27).

Sells (I984) proposes to take the informal term 'preverbal particle' seriously and analyzes $a L$ (and in fact all of the elements here taken to be complementizers) as being adjoined to the finite verb. Two kinds of considerations lead him to this conclusion - the morphosyntactic evidence considered earlier, and the coordination facts seen in (58) (Sells I984: I3I):

(58) (a) an fear a cheannaíonn agus a dhíolann tithe the man aL buy [PRES] and aL sell [PRES] houses 'the man who buys and sells houses'

(b) *an fear a cheannaíonn agus d(h)íolann tithe the man aL buy [PRES] and sell [PRES] houses 'the man who buys and sells houses'

In the framework developed in McCloskey (I990, I996) and in the present paper, the structure assumed by Sells is, in effect, the structure which is the output of the operation of C-lowering. Recall that, according to these proposals, the examples in (59) will present to the morphophonology structures like those seen in (60). (59a) involves the direct relative particle $a L$; (59b) involves the interrogative particle.

(59) (a) an deoch a d- ól tú the drink aL PAST drink you 'the drink that you drank'

(b) A $\quad-r$ ól tú í? INTERR PAST drink you it 'Did you drink it?'

(6o) (a)

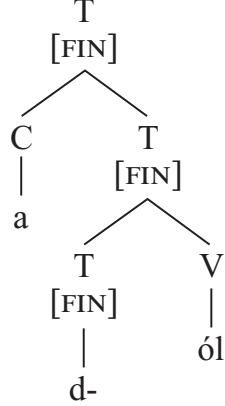

(b) $\mathrm{T}$

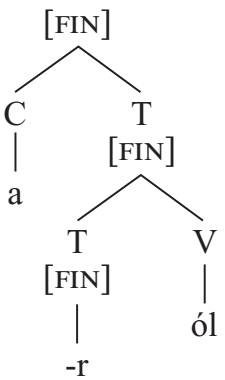

These structures replicate the essential features of Sells' proposal and will account for the coordination evidence in exactly the same way. ${ }^{19}$

This combination of proposals (taking $a L$ and the other preverbal particles

[19] As is well-known, French que, also a prosodic dependent which leans to the right, shows the same pattern of coordination seen in (58). See Godard I989, Sportiche (I999: 207). 
to be members of the category $\mathrm{C}$, but subject to the requirement of adjunction to the finite verb for prosodic and morphological purposes) seems to provide a reasonable way of understanding the full range of their properties.

Duffield (I995) is also primarily concerned with the morphosyntactic properties already dealt with, providing the most detailed and most complete discussion to date of the phenomena. His proposal is similar to that of Sells (I984) in that it assumes that the direct relative particle $a L$ is (at every point in the derivation) adjoined to the functional element $\mathrm{T}$ (ense), to which the finite verb raises:

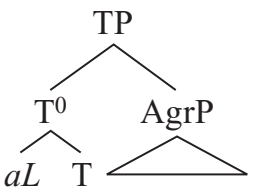

But the proposal differs in two important ways from that in Sells (I984). The first difference is that the structure in (6I) is assumed only for the direct relative particle $a L$, not for the other preverbal particles. These latter are analyzed, as in the present paper, as complementizers (with the important exception of the markers of negation which are treated as being variable in position since they are variable in their mutation effect). Duffield is brought to this conclusion by a detailed consideration of the morphosyntactic patterns we have already considered and responded to in the previous two sections.

The second difference has to do with the larger structures in which complexes like those in (6I) are thought to be embedded. On this, Duffield (I995: I88) considers two possibilities.

One, relatively more conventional, assumes larger structures like (62).

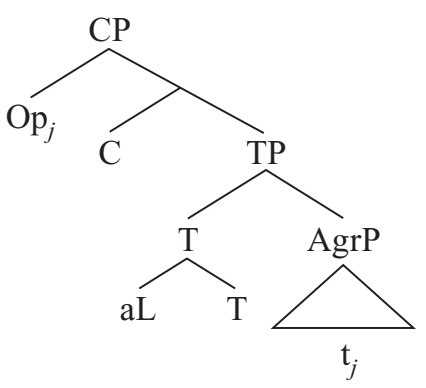

If this structure is adopted, mechanisms will have to be in place to ensure that the right things happen in the C-projection. In particular, no overt element may occupy the $\mathrm{C}$-position (since $a L$ may not, of course, co-occur with any (other) complementizer; this is one of the principal reasons for taking it to be a realization of $\mathrm{C}$ itself). Furthermore, $\mathrm{C}$ in (62) will have to be of a type 
to induce an application of WH-movement (to account for Property Four of pp. 70-72 above). Say that this amounts to its bearing the WH-feature. C[WH] will have to be null and will have to have some property, perhaps selectional, which forces appearance of the particle $a L$ adjoined to $T$ immediately below it. But when elaborated in this way, the proposal is so close to the proposals developed here and in McCloskey (I996) that it is not obvious that they are empirically distinguishable. In the context of those proposals, (62) is the output structure of the PF operation of C-lowering; $\mathrm{C}$ is empty because it has been vacated by movement, and $\mathrm{C}[\mathrm{WH}]$ forces appearance of $a L$ because $a L$ Is the normal morphosyntactic realization of $\mathrm{C}[\mathrm{WH}]$. But there are other ways of implementing the basic insights of McCloskey (I996) (see especially Bobaljik 1995) and an analysis which would take (62) to be the initial syntactic structure and assume covert raising of $a L$ to $\mathrm{C}$ (or agreement without raising) is surely also feasible. ${ }^{20}$ The matter is worth arguing about, but the two analyses seem to me to be close enough, in spirit and in detail, that the task of distinguishing them needn't be taken up in the present paper.

The proposal in (62), however, is not the one that Duffield (I995) ultimately adopts. He suggests, rather (p. I9I), that when $a L$ adjoins to T, its function is to designate TP a Topic projection (in the sense of Müller \& Sternefeld I993). That is, the function of $a L$ is to license Spec,TP as a topic position. To this position raise either contentful XPs (yielding topicalization constructions or 'reduced cleft' constructions like (I I) above) or else null operators (to derive relative clauses and constituent questions).

The trouble with this proposal, it seems to me, is that it is insufficiently general. It is true that among the clauses marked by $a L$ are some that are properly characterized as topicalizations (in various senses of the term 'topicalization'). This is most clear in the case of 'reduced clefts' like (I I). These constructions have a range of pragmatic functions, but when they introduce an indefinite at the beginning of a narrative, their function is to introduce a discourse-new topic. A characteristic way to begin a story, for instance, is as in (63).

(63) Fear a bhí thíos in Anagaire a raibh triúr mac aige. man aL was down in Annagry aN was three sons at-him 'There was this man in Annagry who had three sons.'

It is also true that there is an old tradition connecting relativization with topicalization (see Kuno 1976, Bresnan \& Mchombo 1987 among many others). If one looks only at these constructions, it seems reasonable to connect the appearance of $a L$ with a process of topicalization.

But these two constructions represent only a small subset of the contexts of which $a L$ is characteristic. And when one examines the full range of such

[20] Such an analysis was urged by a reviewer of McCloskey (1996), and has been developed in unpublished work by Ian Roberts (Roberts 1999). 


\section{JAMES MCCLOSKEY}

constructions, it becomes clear that it is by no means a general property of clauses headed by $a L$ that they introduce topics. The characteristic function of full clefts, for instance (like their English counterparts, and also like most reduced clefts), is to introduce a contrastive focus, as seen in particular in their characteristic use in answering $\mathrm{WH}$-questions: ${ }^{21}$

(64) (a) An

$$
\text { tinn a tá sé? }
$$

INTERR + COP sick aL be [PRES] he

'Is it sick that he is?' (as opposed to tired, emotional, drunk)

(b) Ní abhaile a chuaigh sé ach isteach go lár

$\mathrm{NEG}+\mathrm{COP}$ home aL go [PAST] he but in to centre

na cathrach.

the city $[\mathrm{GEN}]$

'It wasn't home he went, but (rather) in to the city-centre.'

Phrases associated with explicit focus markers also occur routinely in this construction:

(65) is ag an Aimsir amháin a tá brí an réitigh.

COP[PRES] at the Time only aL is substance the solution

'Only time will tell.'

Similar remarks apply for the case of WH-questions, given that fronted interrogative phrases are normally construed as foci:

(66)
(a) Céacu mac a thóg $t$ an teach sin? which son aL raise [PAST] the house DEMON
'Which of the sons built that house?'
(b) Caidén t-am a bheas sibh ag imeacht? what time aL be [FUT-WH] you leave [PROG] 'When will you be leaving?'
(c) Caidé mar a rinne tú é? how aL did you it 'How did you do it?'

For the largest range of cases, however, notions like topic and focus (at least if they are given something like their usual interpretations) seem to be simply irrelevant to the characterization of clauses headed by $a L$. It is surely something of a fiction to claim that in comparative and equative clauses, in the various adverbial clauses, in the emphatic negative construction and so on (see examples (8), (9), (I2), (I3), (I4) above), there is a consistent expression of topic-hood.

When the idea that $a L$ is a topic-marker is implemented within the larger framework of Duffield (I995), some additional difficulties emerge. Since it follows in that framework that the indirect relative particle $a N$ must be a

[2I] The discussion here is based closely on that in Ó Siadhail (I989: 237). Ó Siadhail notes: 'This fronting seems to be confined to a contrastive function ...'. Noonan (I997: I29, fn. 30) makes a similar argument. 
complementizer (since it exhibits all the morphosyntactic characteristics said to be diagnostic of the category $\mathrm{C}$ ), the structure of relative clauses involving $a N$ (resumptive pronoun relatives and some adjunct relatives) is necessarily different from the structure of clauses introduced by $a L$. In particular, there is no Topic projection in clauses introduced by $a N$. But it follows then in turn that doublets like those in (67)-(69) are syntactically and pragmatically quite different one from another. In each case, the a-example involves $a L$ and the b-example involves $a N$.

(67) (a) an ghirseach a ghoid na síogaí

the girl aL stole the fairies

'the girl that the fairies stole away'

(b) an ghirseach ar ghoid na síogai í

the girl aN stole the fairies her

'the girl that the fairies stole away'

(68) (a) an lá a bhí muid i nDoire

the day aL be [PAST] we in Derry

'the day that we were in Derry'

(b) an lá a raibh muid i nDoire

the day aN be [PAST] we in Derry

'the day that we were in Derry'

(69) (a) an taisce a tá siad a chuartú

the treasure aL be [PRES] they seek [PROG]

'the treasure that they're looking for'

(b) an taisce a bhfuil siad dhá chuartú

the treasure aN be [PREs] they it seek [PROG]

'the treasure that they're looking for'

In this general framework, (67a), (68a) and (69a) must involve topicalization; (67b), (68b) and (69b) must not involve topicalization. But there is no detectable pragmatic distinction between the a-examples and the b-examples.

Similarly troubling implications follow in the case of (70) and (7I).

(70) (a) fear ar bith a dhéanfadh an méid sin man any aL do [COND] that-much 'any man who would do that much'

(b) fear ar bith nach ndéanfadh an méid sin man any NEG C do [COND] that-much 'any man who wouldn't do that much'

(7I) (a) rud a tá mé ag rá a tá fíor thing aL be [PRES] I say [PROG] aL be [PREs] true 'a thing that I am saying is true'

(b) rud a tá mé ag rá nach bhfuil fíor thing aL be [PRES] I say [PROG] NEG be [PRES] true 'a thing that I am saying is not true' 


\section{JAMES MCCLOSKEY}

(c) rud nach bhfuil mé ag rá a tá fíor thing NEG be [PRES] I say [PROG] aL be [PRES] true 'a thing that I am not saying is true'

The mark of subordinate negation nach passes all of the morphosyntactic tests that have been supposed to identify complementizers. As a consequence (70b), in the system of Duffield (I995), must involve movement through Spec, CP and no Topic projection. (70a), on the other hand, will involve topicalization. But again, there is no detectable pragmatic distinction between the examples. Similar remarks apply in the case of (7I). (7Ia) will involve double topicalization; (7Ib) will involve movement to Spec, CP in the lower clause and topicalization in the higher clause; (7Ic) must involve WHmovement in the lower clause followed by topicalization in the higher. ${ }^{22}$ But once again, the pragmatic consequences that might be expected to follow these syntactic distinctions are undetectable. ${ }^{23}$

Noonan (1997) develops a related but different approach. Accepting the morphosyntactic arguments that $a L$ is not a complementizer, she proposes

[22] The issues discussed in footnote 23 also arise in this case, in that such 'mixed' derivations are said to be impossible, given the proposed analogy to Müller \& Sternefeld's (I993) treatment of German.

[23] An additional worry involves the 'successive-cyclic' aspect of the distribution of $a L$ :

(i) mar a míníodh daoithe a dhéantaí sa tseanam

as aL was-explained to-her aL used-be-done in-the old-time 'as was explained to her used to be done in the old days'

(ii) Cé a dúradh léithi a cheannódh é?

who aL was-said with-her aL would-buy it

'Who was she told would buy it?'

One has to assume that every clause in such cases contains a Topic position. In this respect, Duffield (I995: I9I-I96) makes a connection with the analysis of long A-movement in German developed in Müller \& Sternefeld (1993), and claims (p. I93) as a point of similarity between Müller \& Sternefeld's (I993) data and the Irish data that 'mixed $a L$ and $a N$ chains in long-distance dependencies are always ungrammatical'. This property is said to mirror Müller \& Sternefeld's observation that, in German, Topicalization and WHmovement never interact with one another (that is, Topicalization in a lower clause never feeds WH-movement in a higher clause, and WH-movement in a lower clause never feeds Topicalization in a higher clause). The claim about the Irish facts is not quite accurate, however. It has been known since the earliest work on the topic that such mixed chains, while slightly marked, do occur. See McCloskey (I979: I8ff.), Harlow (I98 I : 244-245), McCloskey (1985: 78), McCloskey (I990: 245, fn. 23), Noonan (I997: I3I), and McCloskey (I997), from which the following (attested) examples are cited:

(i) aon duine a cheap sé a raibh ruainne tobac aige any person aL thought he aN was scrap tobacco at-him 'anyone that he thought had a scrap of tobacco'

(ii) Cé is dóigh leat a bhfuil an t-airgead aige?

who aL-COP[PRES] likely with-you $\mathrm{aN}$ is the money at-him

'Who do you think has the money?'

Exactly similar issues arise with respect to negation - see the text discussion of (70) and (7I). 
that $a L$ (and also the indirect relative particle $a N$ ) is an instance of a functional category $\mathrm{F}$ which occurs below $\mathrm{C}$. This head is identified as the head of a Focus Projection (FP). Apparently unbounded WH-movement is taken to involve cyclic movement through a series of Spec,FP positions, the WH-phrase entering into multiple checking relations with the Focus head (Noonan 1997: I24).

This proposal and the previous one (Duffield's (I995) proposal that $a L$ is a Topic-marker) are in an anti-symbiotic relation with one another. The observations which make one plausible make the other implausible and vice versa, and the fact that both proposals have been made is an indication, I think, of what is wrong.

There are indeed cases, as we have just seen, in which $a L$ marks a focus structure of one kind or another. These are the cases which are troublesome for the claim that $a L$ determines a Topic projection. But equally, there is a range of cases in which $a L$ is in fact associated with topicalization of one kind or another (see example (63) above and associated discussion). These are the cases which are troublesome for the claim that $a L$ determines a Focus projection. And finally there is a range of constructions for which neither categorization seems right (adverbial clauses, comparative and equative clauses and so on). What is distinctively absent is a single pragmatic or discourse-sensitive function that is common to all $a L$-constructions (or even one that predominates). Or at least, notions like 'topic' and 'focus' can be applied to the generality of $a L$-constructions only at the risk of bleaching those terms of substantive and empirical content. ${ }^{24}$

There is something, though, which all clauses headed by $a L$ share. This is the overt operator-variable binding of which $a L$ is the morphosyntactic mark. The variable-binding so marked can be put to use in a variety of pragmatic and discourse-sensitive ways. That is, the range of $a L$ constructions is just the range of $\mathrm{WH}$-constructions, as originally identified by Chomsky (I977), with their variety of discourse and pragmatic functions. ${ }^{25}$

[24] To deal with cases in which there is 'long movement' from an embedded clause, Noonan (I997: I24) assumes that there is a Focus Projection in each clause through which the WHoperator moves. This is a necessary assumption, since, as we have seen, $a L$ heads each clause out of which a WH-phrase is extracted. The assumption is at odds, though, with the evidence that suggests that a Focus projection may be present in a main clause, or in an embedded clause, but not in both simultaneously-and probably for principled reasons - see Rizzi (1997: 329).

[25] Another approach to this body of data was suggested by Noonan (I992). This account takes $a L$ to be implicated in the Case and Agreement licensing system of the language. The particle $a L$ is taken to be: 'a reflex of a Case agreement configuration and derives from the Case-checking of the operator in its S-structure position' (Noonan I992: I43). Two kinds of consideration lead to this line of analysis - the morphosyntactic patterns which supposedly suggest that $a L$ is not a complementizer, and the goal of accounting for the distributional restrictions on the use of $a L$, which is taken to be restricted to extraction of bare DP-arguments (Noonan I992: I38). We have discussed the morphosyntactic issues at length already. As to the second point, the problem is that the distribution of $a L$ is not 
The search (so far fruitless, it seems to me) for some other function or label to assign to the element $a L$ is driven largely by the morphosyntactic concerns reviewed and discussed earlier. Since these considerations are taken to show that $a L$ is not a member of the category $\mathrm{C}$, some alternative categorization must be sought (Noonan 1997: I24-5). The fact that no plausible alternative candidate has so far been identified reinforces the conclusion, it seems to me, that those morphosyntactic criteria are not in any straightforward way revealing about syntactic category-membership.

The proposals developed in Noonan (I997) go far beyond what has been discussed here. The primary aim of the analysis developed is to provide an account of the relative distribution of the direct and indirect relative particles $(a L$ and $a N$ ) which takes as its starting point the idea that both particles belong to the same syntactic category (both are members of $F$ but they have different derivational fates). The intuition behind this analysis seems to me to be entirely right, but the discussion here suggests that the unification will be better worked out in a system in which both particles are taken to belong to C. I develop such an account in other work (McCloskey 1997).

\section{Articulating the C-system}

Finally, we can turn to the question of where this body of observation and argumentation will figure in the system of Rizzi (1997). Rizzi argues that CP should be regarded not as a unitary X-bar projection but rather as a hierarchical sequence of projections, the highest of which specifies 'force' (or 'clause-type' in the sense of Cheng I99I), the lowest of which specifies finiteness. That is, the traditional (72a) should rather be understood as (72b).

(72) (a)

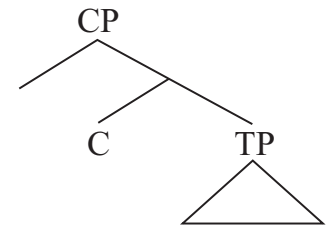

(b)

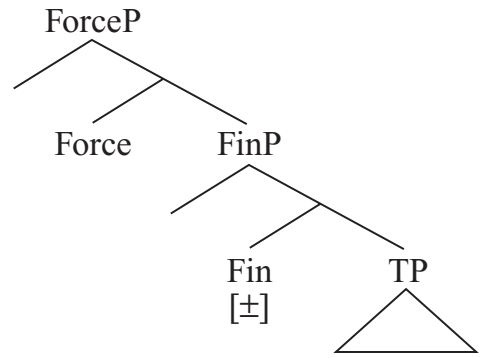

restricted in the way it suggests. Use of $a L$ is characteristic of a wide range of constructions (many of them exemplified earlier in this paper) which do not involve extraction of NP (DP), and which do not involve extraction of an argument - among others, extraction of PP-arguments, XP-predicates and adjuncts in clefts, extraction of predicates in comparative and equative clauses, and extraction of adjuncts in relative clauses and questions. For these kinds of reasons, and others, the proposal is withdrawn in Noonan (I997: I22, fn. I7). Unfortunately, the difficulty persists in the account offered of the distribution of $a L$ in Noonan (1997), where the $a L$-variant of the Focus head is taken to be a Case-licenser, and therefore permits in its specifier only elements (DP and CP) which are subject to Caselicensing. 
These two projections constitute the skeleton of the $\mathrm{C}$-system and are always present. The higher head expresses the fact that a given clause is interrogative, declarative, relative, subordinate or the like, and is, as a consequence, open to selection by a governing element; the lower is an expression of finiteness and enters into an agreement-like relation with the (independent) Tense specification of TP (for Rizzi actually AgrSP).

Intervening between the highest and the lowest of these projections is the Topic/Focus system - at most one Focus projection, and possibly many Topic projections. These projections are present 'as needed' and are absent in structures which lack topicalized or focussed elements. WH-movement in relative clauses is analyzed as movement into the specifier of the highest ('force') projection; WH-movement in root questions is taken to be movement into a Focus projection.

We have already surveyed the evidence which suggests that the preverbal particles in Irish do not encode Topic-hood or Focus. Many of the particles (declarative $g o$, interrogative $a^{\prime}$, the instance of $a L$ which occurs in embedded questions, the particles selected by 'subordinators' such as sul 'before' and so on) must be available for selection and must therefore be associated with the highest ('Force') projection of the C-system. If Rizzi (1997) is correct in maintaining that relative clause WH-movement is movement to the highest specifier of the C-system, then there is further reason to believe that $a L$ occupies the head of the 'Force' projection. ${ }^{26}$

All of these particles, however, also encode finiteness (in the fact that they occur only in finite clauses).

A way of interpreting this cluster of properties within Rizzi's system would be to hold that the particles are syncretic expressions of the two obligatory heads of the C-system. ${ }^{27}$ In the case of $a L$, for instance, we will have, as before, the specifications [WH] and [FIN], spelled out as the morphophonological bundle $\mathrm{F}_{a L}$ (including the property of inducing lenition). Such an element would be licensed by appearing first in the lower head (where the [FIN] feature is checked) and then raising to the higher head, Force, where the [WH] feature is checked. Such an analysis is close to Rizzi's (I997: 3 I2) treatment of English that. ${ }^{28}$

On this view, the crucial property of 'singularity' - the fact that $a L$ may not co-occur with any other C-element - is ensured by the fact that it, as a

[26] Rizzi (1997) suggests tentatively that root WH-questions involve movement to the Focus projection. It has long been recognized, though, that constituent questions in Irish are more similar to relative clauses (or clefts) than are their English counterparts (McCloskey (I979: 5I-55), Duffield (I995: I69)).

[27] An analysis along these lines is developed independently by Ian Roberts in ongoing work (Roberts I999).

[28] It might be possible within this overall scheme to analyze the two past tense markers $d$-and $-r$ as being instantiations of the lower C-head, rather than as instantiations of Tense, as assumed in the text (this is, I think, the position of Cottel 1995). It is not clear to me how to resolve this issue. 
lexical item, encodes two features ('finiteness' and 'WH-ness') which are distributed syntactically across two distinct phrase structural positions. $A L$ must then occupy both positions (at different derivational stages) in order to have its component features legitimized. As a consequence, no other element may occupy either position.

As far as I have been able to tell, this proposal does not add to our understanding of any of the Irish-internal facts, but is compatible with them. The choice between it and the proposal that there is a single C-projection will need to be made on other grounds, I believe.

\section{SUMmaRY AND CONCLUSION}

The debate (now twenty years old) concerning these questions has been empirically rich, and it has been important in pushing analytical work on Irish further and deeper. The terms of the debate have shifted over the years - as theories have shifted, and as more detailed treatments of the morphosyntactic facts have been attempted. The overall analysis defended in this paper is, as a consequence, a composite of many proposals that have been developed by different people over the years. It does, though, preserve some of the core elements of the analysis developed originally some twenty years ago. Specifically, the particle $a L$ is a member of the category $\mathrm{C}$ whose defining characteristic is that it bears the WH-feature. As such, it (re)emerges as providing important overt evidence for a postulate that was otherwise and originally developed on the basis of quite abstract theoretical deduction. There are always grounds for optimism when abstract theoretical deduction and the drive towards depth and detail in empirical coverage converge on a single conclusion.

\section{REFERENCES}

Armstrong, J. (I975). A note on initial mutation in Modern Irish. Linguistic Inquiry 6. 3 I 7-323. Bobaljik, J. (I995). Morphosyntax: the syntax of verbal inflection. Ph.D. dissertation, MIT.

Bresnan, J. \& Mchombo, S. (I987). Topic, pronoun, and agreement in Chicheŵa. Language 63. $74 \mathrm{I}-782$.

Cheng, L. (I99I). On the typology of wh-questions. Ph.D. dissertation, MIT.

Chomsky, N. (1977). On wh-movement. In Akmajian, A., Culicover, P. \& Wasow, T. (eds.), Formal syntax. New York \& San Diego: Academic Press. 7I-I 32.

Chomsky, N. (1995). The Minimalist Program. Cambridge, MA: MIT Press.

Chomsky, N. (I998). Minimalist inquiries, the framework. Ms., MIT.

Christian Brothers (1960). Graiméar Gaeilge na mBráithre Críostai. Dublin: Mac an Ghoill Teoranta.

Chung, S. \& McCloskey, J. (I987). Government, barriers and small clauses in Modern Irish. Linguistic Inquiry I8. I73-237.

Collins, C. (I996). Local economy. Cambridge, MA: MIT Press.

Cottel, S. (1995). The representation of tense in Modern Irish. In Starke, M., Haeberli, E. \& Laenzlinger, C. (eds.), GenGenP (Geneva Generative Papers) 3.2. Département de Linguistique Générale, Université de Genève. I05-I24.

De Bhaldraithe, T. (1953). Gaeilge Chois Fhairrge: An deilbhiocht. Dublin, Ireland: Institute for Advanced Studies. 


\section{MORPHOSYNTAX OF WH-EXTRACTION IN IRISH}

den Besten, H. (I983). On the interaction of root transformations and lexical deletive rules. In Abraham, W. (ed.), On the formal syntax of the West Germania. Amsterdam: Benjamins. 47-I3I.

Duffield, N. (1995). Particles and projections in Irish syntax. Dordrecht: Kluwer.

Godard, D. (1989). Empty categories as subjects of tensed Ss in English or French. Linguistic Inquiry 20. 497-506.

Guilfoyle, E. (1990). Functional categories and phrase structure parameters. Ph.D. dissertation, McGill University, Montreal, Canada.

Hale, K. (1978). Obviation in Irish. Ms., MIT.

Harlow, S. (198I). Government and relativization in Celtic. In Heny, F. (ed.), Binding and filtering. Cambridge, MA: MIT Press.

Harlow, S. (1983). Celtic relatives. York Papers in Linguistics I0. 77-I2 I.

Kayne, R. (I983). Chains, categories external to S, and French complex inversion. Natural Language \& Linguistic Theory I. I09-I37.

Kuno, S. (1976). Subject, theme, and the speaker's empathy. In Li, C. N. (ed.), Subject and topic. New York \& San Diego: Academic Press. 4I7-444.

Lasnik, H. \& Saito, M. (I992). Move $\alpha$ : conditions on its application and output. Cambridge, MA: MIT Press.

Lucas, L. (I979). Grammar of Ros Goill Irish Co. Donegal. Belfast, Northern Ireland: Institute of Irish Studies.

McCloskey, J. (1976). Conditions on transformations in Modern Irish. In Kegl, J., Nash, D. \& Zaenen, A. (eds.), NELS VII, Proceedings of the Seventh Annual Meeting of the North Eastern Linguistics Society.

McCloskey, J. (1977). An acceptable ambiguity in Modern Irish. Linguistic Inquiry 8. 604-609.

McCloskey, J. (I979). Transformational syntax and model theoretic semantics: a case-study in Modern Irish. Dordrecht: Reidel.

McCloskey, J. (I985). The Modern Irish double relative and syntactic binding. Ériu 36. 45-84.

McCloskey, J. (I990). Resumptive pronouns, A-binding and levels of representation in Irish. In Hendrick, R. (ed.), Syntax of the modern Celtic languages. New York \& San Diego: Academic Press. I99-248.

McCloskey, J. (1996). On the scope of verb raising in Irish. Natural Language \& Linguistic Theory I4. 47-I04.

McCloskey, J. (I997). Movement, resumption and complementizer choice. Ms., University of California, Santa Cruz. Paper presented to the Second Celtic Linguistics Conference, University College Dublin, June I997.

Müller, G. \& Sternefeld, W. (1993). Improper movement and unambiguous binding. Linguistic Inquiry 24. 46 $\mathrm{I}-508$.

Noonan, M. (1992). Case and syntactic geometry. Ph.D. dissertation, McGill University, Montreal, Canada.

Noonan, M. (1994). The that-trace filter and wh-agreement in Irish. Ms., York University, Toronto. Paper presented to the International Conference on Language in Ireland, University of Ulster, Jordanstown, Northern Ireland, June I994.

Noonan, M. (1997). Functional architecture and wh-movement: Irish as a case in point. Canadian Journal of Linguistics $\mathbf{4 2}$. I I I-I39.

Noonan, M. (I999). What is the true nature of successive cyclic wh-movement? Ms., York University, Toronto. Paper presented to the Eighteenth Annual Meeting of the West Coast Conference on Formal Linguistics. University of Arizona, Tucson, March I999.

Ó Sé, D. (1983). Gaeilge Chorca Dhuibhne: An fhoneolaiocht agus an deilbhiocht. Ph.D. dissertation, University College Dublin, Dublin, Ireland.

Ó Searcaigh, S. (1939). Coimhréir Ghaedhilg an Tuaiscirt. Dublin, Ireland: Government Publications Office.

Ó Siadhail, M. (1980). Diabhal (deamhan \& rl) mar dheis chomhréire sa nGaeilge. Ériu 3I. 46-58.

Ó Siadhail, M. (1989). Modern Irish: grammatical structure and dialectal variation. Cambridge \& New York: Cambridge University Press.

Rizzi, L. (I990). Relativized minimality. Cambridge, MA: MIT Press.

Rizzi, L. (I997). The fine structure of the left periphery. In Haegeman, L. (ed.), Elements of grammar: handbook of generative syntax. Dordrecht: Kluwer. 28 I-337. 


\section{JAMES MCCLOSKEY}

Rizzi, L. \& Roberts, I. (I989). Complex inversion in French. Probus I. I-30.

Roberts, I. (I999). Ms., University of Stuttgart. Paper presented to the 6th Welsh Syntax Seminar, Gregynog, Wales, June 24th I999.

Sells, P. (1984). Syntax and semantics of resumptive pronouns. Ph.D. dissertation, University of Massachusetts, Amherst.

Shlonsky, U. (1992). Resumptive pronouns as a last resort. Linguistic Inquiry 23. 443-468.

Sportiche, D. (I999). Subject clitics in French and Romance: complex inversion and clitic doubling. In Johnson, K. \& Roberts, I. (eds.), Beyond Principles and Parameters: essays in memory of Osvaldo Jaeggli. Dordrecht: Kluwer. I89-22I.

Stenson, N. (198I). Studies in Irish syntax. Tübingen: Max Niemeyer Verlag.

Vikner, S. (199I). Verb movement and the licensing of NP-positions in the Germanic languages. Ph.D. dissertation, Université de Genève, Geneva, Switzerland.

Author's address: Stevenson College,

University of California, Santa Cruz,

Santa Cruz, CA 95064.

U.S.A.

E-mail:mcclosk@ling.ucsc.edu 